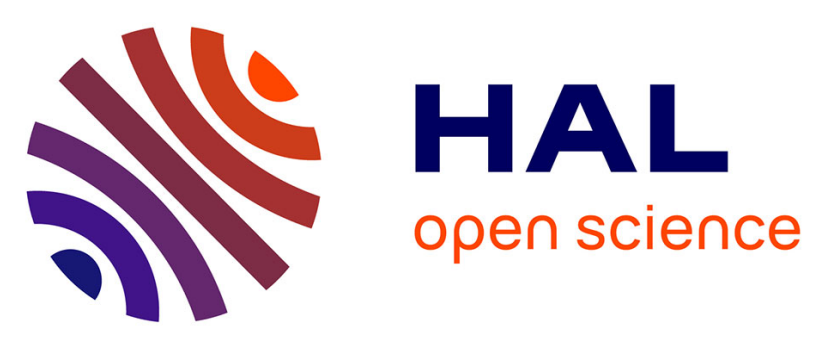

\title{
Synthesis of Carbon-Nitrogen-Phosphorous Materials with an Unprecedented High Amount of Phosphorous toward an Efficient Fire-Retardant Material
}

Wenyao Zhang, Jesffls Barrio, Christel Gervais, Andraz Kocjan, Aiping Yu, Xin Wang, Menny Shalom

\section{To cite this version:}

Wenyao Zhang, Jesffls Barrio, Christel Gervais, Andraz Kocjan, Aiping Yu, et al.. Synthesis of CarbonNitrogen-Phosphorous Materials with an Unprecedented High Amount of Phosphorous toward an Efficient Fire-Retardant Material. Angewandte Chemie International Edition, 2018, 57 (31), pp.97649769. 10.1002/anie.201805279 . hal-02126740

\section{HAL Id: hal-02126740 \\ https: / hal.sorbonne-universite.fr/hal-02126740}

Submitted on 25 Feb 2021

HAL is a multi-disciplinary open access archive for the deposit and dissemination of scientific research documents, whether they are published or not. The documents may come from teaching and research institutions in France or abroad, or from public or private research centers.
L'archive ouverte pluridisciplinaire HAL, est destinée au dépôt et à la diffusion de documents scientifiques de niveau recherche, publiés ou non, émanant des établissements d'enseignement et de recherche français ou étrangers, des laboratoires publics ou privés. 


\title{
Synthesis of Carbon-Nitrogen-Phosphorous Materials with an Unprecedented High Amount of Phosphorous toward an Efficient Fire-Retardant Material
}

\author{
Wenyao Zhang, Jesús Barrio, Christel Gervais, Andraž Kocjan, Aiping Yu, Xin Wang,* and \\ Menny Shalom*
}

\begin{abstract}
Phosphorus incorporation into carbon can greatly modify its chemical, electronic, and thermal stability properties. To date this has been limited to low levels of phosphorus. Now a simple, large-scale synthesis of carbon-nitrogenphosphorus (CNP) materials is reported with tunable elemental composition, leading to excellent thermal stability to oxidation and fire-retardant properties. The synthesis consists of using monomers that are liquid at high temperatures as the reaction precursors. The molten-state stage leads to good monomer miscibility and enhanced reactivity at high temperatures and formation of CNP materials with up to $32 w t \%$ phosphorus incorporation. The CNP composition and fireretardant properties can be tuned by modifying the starting monomers ratio and the final calcination temperature. The CNP materials demonstrate great resistance to oxidation and excellent fire-retardant properties, with up to $90 \%$ of the materials preserved upon heating to $800^{\circ} \mathrm{C}$ in air.
\end{abstract}

Carbon materials are widely used for a range of applications such as batteries, supercapacitors, fuel cells, heterogeneous

[*] Dr. W. Zhang, J. Barrio, Prof. M. Shalom

Department of Chemistry and Ilse Katz Institute for Nanoscale Science and Technology, Ben-Gurion University of the Negev Beer-Sheva 8410501 (Israel)

E-mail:mennysh@bgu.ac.il

Dr. W. Zhang, Prof. X. Wang

Key Laboratory of Soft Chemistry and Functional Materials

Nanjing University of Science and Technology

Nanjing 210094 (China)

E-mail:wangx@njust.edu.cn

Dr. W. Zhang

Colloid Chemistry Department Department

Max Planck Institute for Colloids and Interfaces

Potsdam 14424 (Germany)

Dr. W. Zhang, Prof. A. Yu

Waterloo Institute for Nanotechnology, University of Waterloo Waterloo, Ontario N2L3G1 (Canada)

Prof. C. Gervais

Sorbonne Université, Collège de France, Laboratoire de Chimie de la Matière Condensée de Paris (LCMCP), UPMC Universite Paris 6, UMR CNRS 7574

4 place Jussieu, 75252 Paris cedex 05 (France)

Dr. A. Kocjan

Department for Nanostructured Materials, Jožef Stefan Institute Ljubljana (Slovenia)

(-) Supporting information and the ORCID identification number(s) for

(DD the author(s) of this article can be found under:

https://doi.org/10.1002/anie.201805279. catalysis, sensors, water treatment, among others. ${ }^{[1]}$ Insertion of heteroatoms with a different electronegativity into the carbon network can dramatically alter its electronic, ${ }^{[2]}$ magnetic, ${ }^{[3]}$ optical, ${ }^{[4]}$ and electrochemical properties ${ }^{[5]}$ along with its chemical reactivity. ${ }^{[6]}$ For example, several studies have shown that the introduction of nitrogen and phosphorus as electron donors into a carbon structure alters its electronic states, ${ }^{[7]}$ (electro)catalytic properties ${ }^{[8]}$ and its chemical stability to both oxidation and exposition to high temperatures. ${ }^{[9]}$ More specifically, doping a carbon matrix with phosphorus significantly enhances its thermal stability ${ }^{[10]}$ and its electrical conductivity. ${ }^{[11]}$

The covalent radius of nitrogen permits its facile incorporation into carbon materials; structures with up to $70 \%$ nitrogen are easily synthesized. ${ }^{[12]}$ In contrast, the large covalent radius of phosphorus strongly impedes its insertion into the carbon matrix. During the traditional solid-state synthesis of carbon materials, the carbon and nitrogen atoms can build a uniform network which is energetically favorable, whereas the phosphorus is mainly bonded to oxygen and carbon atoms on the surface. ${ }^{[7 b, 13]}$ Furthermore, in materials based on carbon and nitrogen, the phosphorus is seldom bonded to nitrogen atoms. Therefore, up to now, only carbon materials doped with low amounts of phosphorus have been prepared and the presence of $\mathrm{P}-\mathrm{N}$ bonds within the carbon structure has rarely been reported. ${ }^{[7 b, 14]}$ Its presence within a carbon network can strongly enhance its chemical and thermal stability, ${ }^{[15]}$ as well as its electronic and catalytic properties. ${ }^{[16]}$ Polyphosphazenes are polymers with a $\mathrm{P}-\mathrm{N}$ backbone, which are usually prepared from poly(dichlorophosphazene). The synthesis of the latter usually requires a highly inert environment and involves the use of catalysts to avoid crosslinking. ${ }^{[17]}$

Herein, we report the simple and large-scale synthesis of carbon-nitrogen-phosphorus materials with a large amount of heteroatoms incorporation and up to $32 \mathrm{wt} \%$ phosphorus in the final materials. The new materials were obtained by the calcination of mixtures of two monomers, namely hexachlorophosphazene (abbreviated as $\mathrm{PNCl}$ ) and 2,4-diamino-6phenyl-1,3,5-triazine (DPT), which form a uniform liquid solution at high temperatures $\left(250-400^{\circ} \mathrm{C}\right)$. The liquid state facilitates the ring-opening of $\mathrm{PNCl}$ to poly(dichlorophosphazene), followed by their reaction with amines groups in DPT. Subsequently, upon condensation at high temperatures, a range of new carbon-nitrogen-phosphorus materials are formed; their properties can be tuned by changing the initial monomers composition and the final reaction temperature. 
The synthetic route, intermediates, and final materials structure were thoroughly studied by a wide range of techniques. The optimal nanocomposites demonstrate very high stability to oxidation and act as efficient fire-retardant materials.

The carbon-nitrogen-phosphorus materials were synthesized through a reaction involving a molten-state step and a final solid-state condensation as shown in Figure $1 \mathrm{a}$. Briefly, DPT and $\mathrm{PNCl}$ powders in various molar ratios $(6: 1,3: 1,1: 1$, $1: 3$ and 1:6) were ground into a homogeneous solid mixture. Afterward, the mixture was transferred into a ceramic crucible and heated to $260^{\circ} \mathrm{C}$ for $2 \mathrm{~h}$, followed by its calcination under nitrogen atmosphere for another $2 \mathrm{~h}$ at a designated target temperature $\left(450,550,650,750,850^{\circ} \mathrm{C}\right)$. The obtained composites were labeled as $\mathrm{D}_{x} \mathrm{PN}_{y}-\mathrm{T}(x: y$ denotes the molar ratio of DPT to $\mathrm{PNCl}, \mathrm{T}$ denotes the target temperature of the reaction). The reaction yields are given in the Supporting Information, Table S1. The molten-state step allows to shape the final structure as exemplified in Figure $1 \mathrm{a}$. The cylinder shape can be prepared by preforming the reaction in a glass-tube. The confined reaction vessel together with polyphosphazene structure lead to the formation of CNP monolith.

X-ray photoelectron spectroscopy (XPS) measurements show the typical evolution of the chemical states of $\mathrm{P}, \mathrm{C}$, and $\mathrm{N}$ for all samples. The $\mathrm{P} 2 \mathrm{p}$ spectrum reveals four phosphorus environments (Figure $1 \mathrm{~b}$ ). Two dominant species, attributed to the terminal and bridging $\mathrm{P}$ environments from the backbone of $-[\mathrm{PNR}]_{n}-$ polymer chains, appeared in all samples. Importantly, the increase of DPT in the precursor mixture led to a small shift of $\mathrm{P} 2 \mathrm{p}$ to lower binding energies. This shift is due to the electron-donating substituents, from the branched phenyl-modified carbon nitride $\left(\mathrm{Ph}-\mathrm{CN}_{x}\right)$ that is covalently bonded to the $\mathrm{PN}$ chain. Additionally, the spectrum for $\mathrm{D}_{6} \mathrm{PN}_{1}-550$ showed two shoulder peaks, attributed to $\mathrm{P} 2 \mathrm{p}_{3 / 2}$ and $\mathrm{P} 2 \mathrm{p}_{1 / 2}$, at lower binding energies, which correspond to the ternary $\mathrm{P}$ atoms from $\mathrm{PN}$ chain end-groups. This suggests that at high DPT amount mainly $\mathrm{Ph}-\mathrm{CN}_{x}$ is formed and the polymerization with $\mathrm{PNCl}$ is inhibited. Consequently, in the final structure, the result of $\mathrm{PNCl}$ condensation mostly consists of PN oligomers. The detailed reaction paths and the effect of monomers ratio are discussed below.

$\mathrm{C} 1 \mathrm{~s}$ and $\mathrm{N}$ 1s XPS measurements show the evolution of $\mathrm{CN}$ heterocycles ( $\mathrm{C}$ and $\mathrm{N}$ atoms in $\mathrm{C}-\mathrm{N}=\mathrm{C}$ and $\mathrm{N}-(\mathrm{C})_{3}$ species) at high amounts of DPT in the starting materials reflecting the $\mathrm{Ph}-\mathrm{CN}_{x}$ formation. The substitution of $\mathrm{PN}$ structure with $\mathrm{Ph}-\mathrm{CN}_{x}$ was further supported by X-ray diffraction (XRD) measurements, ${ }^{[26]}$ Fourier transform infrared (FTIR) spectroscopy, and elemental analysis (EA) data. The XRD patterns (Supporting Information, Figure S1a) reveal that increasing the relative amount of DPT results in the formation of more organized layered structure, as witnessed by the typical stacking peak of carbon nitride gradually appearing and shifting to higher angles, at around $27.5^{\circ}$. The FTIR spectrum of $\mathrm{D}_{1} \mathrm{PN}_{6}-550$ (Supporting Information, Figure S1b) featured strong and broad absorption bands at $1180 \mathrm{~cm}^{-1}$ and $874 \mathrm{~cm}^{-1}$, corresponding to stretching $\mathrm{P}=\mathrm{N}^{[18]}$ and $\mathrm{P}-\mathrm{N}$ vibrations, ${ }^{[19]}$ respectively. For materials prepared with a larger relative amount of DPT, the typical peaks corresponding to i) the breathing vibration mode of tris-triazine subunits at $810 \mathrm{~cm}^{-1}$ and ii) vibrations of aromatic $\mathrm{C}-\mathrm{N}$ heterocycles at $1200-1600 \mathrm{~cm}^{-1}$ were detected. EA measurements (Supporting Information, Table S2, Table S4) show that the starting monomers ratio is directly related to the relative amounts of elements in the final materials: the relative increase in DPT resulted in more $\mathrm{C}, \mathrm{N}$ and less $\mathrm{P}, \mathrm{Cl}$ in the final materials and vice versa. The $\mathrm{C} / \mathrm{N}$ atomic ratio approached that for $\mathrm{Ph}-\mathrm{CN}_{x}$ when using higher DPT/PNCl ratio.

All the above-mentioned measurements suggest that the synthesis involves first the ring opening into linear $-[\mathrm{PNCl}]_{n}-$, followed by its substitution with DPT monomers. Afterward, the attached DPT monomers are further condensed into $\mathrm{Ph}^{-}$ $\mathrm{CN}_{x}$. The alteration of the products by the change of the monomers ratio indicates that there is a competition between the DPT condensation and its reaction with the linear PN polymer.

In the next set of experiments, the effect of the final condensation temperature was explored. The thermal properties that are presented later in this manuscript indicate that the $\mathrm{D}_{1} \mathrm{PN}_{3}$ sample is the most stable to oxidation at high temperature, so we focused on further studying materials of this composition at different calcination temperatures. The C 1s high-resolution XPS spectrum of the $\mathrm{D}_{1} \mathrm{PN}_{3}-450$ sample confirms the creation of $\mathrm{Ph}-\mathrm{CN}_{x}$ phase (Supporting Information, Figure $\mathrm{S} 2$ ) and $\mathrm{C}-\mathrm{N}$ and $\mathrm{C}=\mathrm{N}$ bonds were detected. These carbon components show a negligible change upon calcination at $450-650^{\circ} \mathrm{C}$, suggesting that the basic structure of $\mathrm{D}_{1} \mathrm{PN}_{3}$ was undamaged with increasing temperature. Further increase of the calcination temperature to $750^{\circ} \mathrm{C}$ leads to small decomposition of the structure. At $850^{\circ} \mathrm{C}$, most 
of the functional groups disappeared and mainly $\mathrm{sp}^{2}$ carbon was detected, accounting for the collapse of the polymer structure. As reported in heteroatom-doped carbon materials, the dopant atoms incorporate into the $\pi$-conjugated system by delocalizing their p-electrons, ${ }^{[20]}$ this process occurs at $700{ }^{\circ} \mathrm{C}$ or higher temperatures owing to the formation of thermodynamically stable hybridized carbon. This carbonization process can also be evidenced by the additional new peaks in $\mathrm{P} 2 \mathrm{p}$ and $\mathrm{N} 1 \mathrm{~s}$ XPS spectra comparing $\mathrm{D}_{1} \mathrm{PN}_{3}-850$ samples with the materials that were calcinated at lower temperatures. Apart from XPS, EA and ICP data (Supporting Information, Table S3) were used to demonstrate the variation of the elements ratio at $\mathrm{D}_{1} \mathrm{PN}_{3}$ with varying calcination temperatures. The EA data shows that up to $750{ }^{\circ} \mathrm{C}$, the structure remained almost intact and more than $30 \% \mathrm{P}$ was incorporated within the structure. The increase in temperature to $850^{\circ} \mathrm{C}$ resulted in the loss of most $\mathrm{P}$ and only $6 \%$ was detected.

To reveal the reaction mechanism of $\mathrm{DPT} / \mathrm{PNCl}$ we focused on the elucidation of the synthesis path for the $\mathrm{D}_{1} \mathrm{PN}_{3}$ sample. A melting point apparatus (MPA), solid-state NMR, scanning electron microscope (SEM), and also thermogravimetric analysis (TGA) and differential thermogravimetry (DTG) were employed to study the growth mechanism, intermediate and final materials. Figure 2 a displays photographs of DPT-PNCl mixture (molar ratio of 1:3) in a capillary tube heated at various temperatures in the MPA. Two changes can be observed from the MPA images; first, the solid mixture turned into a quicksand-like mixture at $115^{\circ} \mathrm{C}$ owing to the melting of PNCl. Afterward, slightly before $260^{\circ} \mathrm{C}$ the DPT was melted and a transparent homogeneous molten solution was observed. In accordance with the MPA data, TGA and DTG curves (Supporting Information, Figure S3) show that a significant weight loss occurs from $115-200^{\circ} \mathrm{C}$ due to the monomers phase change, followed by their condensation up to $600^{\circ} \mathrm{C}$.

To confirm the critical role of the molten phase, we performed a series of modifications to the reported synthesis. In our experiments, calcination of $\mathrm{PNCl}$ alone led to its full decomposition and no material remained after the same synthetic procedure. The importance of choosing two monomers that form a homogeneous molten state is demonstrated by replacing DPT with other nitrogen-rich organic compounds, namely dicyandiamide, melamine, and urea, which are the common precursors to materials based on carbon and nitrogen: none of these monomers exhibit a clear molten phase. When mixed with $\mathrm{PNCl}$ and calcinated at high temperatures, they did not form a molten phase: as a result, the $\mathrm{PNCl}$ completely evaporated and only carbon-nitrogen materials with a negligible amount of $\mathrm{P}$ were formed with non-uniform distribution (Supporting Information, Figures S4, S5).

Solid-state NMR measurements at various reaction temperatures were acquired to elucidate the reaction path as well the intermediates and final materials structure. ${ }^{13} \mathrm{C} \mathrm{CP}$ MAS spectrum of DPT molecule shows two broad signals centered at 130 and $170 \mathrm{ppm}$, corresponding to carbon within the phenyl and triazine units, respectively (Figure 3a). A more precise assignment was obtained from the calculation of ${ }^{13} \mathrm{C}$ chemical shift values on the crystalline structure of DPT. ${ }^{[21]}$ The full chemical shift values assignments are summarized in the Supporting Information, Table S5. Little change is observed in the carbon environments upon the reaction with $\mathrm{PNCl}$ at $260^{\circ} \mathrm{C}(1: 3$ molar ratio of $\mathrm{DPT}: \mathrm{PNCl})$ as illustrated by a broadening of the ${ }^{13} \mathrm{C}$ signals without significant shifts (Figure $3 \mathrm{a}$.). After heating to $550{ }^{\circ} \mathrm{C}$, the

${ }^{13} \mathrm{C}$ signals remain in the same chemical shift range and only a significant broadening of the signals was observed, which is probably due to the carbonization of the structure, suggesting the formation of graphitic carbon nitride ${ }^{[22]}$ and aromatic carbon domains. ${ }^{[23]}$ 
${ }^{31} \mathrm{P}$ MAS spectrum of $\mathrm{PNCl}$ shows two narrow signals at 18.8 and $17.6 \mathrm{ppm}$ (Figure $3 \mathrm{~b}$ ) that can be attributed to the two phosphorous inequivalent sites (1:2 ratio) in the crystalline structure. ${ }^{[2]}$ After reaction with DPT at $260^{\circ} \mathrm{C}$, the spectrum was drastically changed and broad signals ranging from 10 to $-40 \mathrm{ppm}$ appeared. The prominent changes are probably due to the formation of $\mathrm{PN}_{3} \mathrm{Cl}$ and $\mathrm{PN}_{4}$ environments owing to the replacement of $\mathrm{Cl}$ group with the $\mathrm{NH}_{2}$ groups. To further elucidate the $\mathrm{P}$ chemical environment, we applied structural modeling (Figure $3 \mathrm{c}$ ) to calculate the possible ${ }^{31} \mathrm{P}$ chemical shift values (Supporting Information, Table S6) on simple systems with representative phosphorus first neighbors. The absence of signals between 20 and $50 \mathrm{ppm}$, where peaks for $\left[\mathrm{PCl}_{2} \mathrm{~N}\right]_{3}$ rings would be expected, confirmed the opening of $\left[\mathrm{PCl}_{2} \mathrm{~N}\right]_{3}$ rings.

The formation of $\mathrm{P}-\mathrm{N}$ bonds leads to phosphorous environments which match our experimental data. Indeed, the calculated chemical shift values for $\mathrm{P}(\mathrm{NP})_{x}(\mathrm{NH})_{4-x}$ and $\mathrm{P}(\mathrm{NP})_{2}(\mathrm{NH}) \mathrm{Cl}$ cover the whole experimental observed range. This suggests a large distribution of $\mathrm{P}$ environments at $550^{\circ} \mathrm{C}$. A more precise assignment would necessitate a much more sophisticated modeling, but it can be noticed that after calcination at $850^{\circ} \mathrm{C}$ (Supporting Information, Figure S6) the signal becomes narrower and centered around $-3 \mathrm{ppm}$. This suggests the DPN lost most of its P and turns into carbon, in a good agreement with XPS and EA results.

Having all the data at hand we suggest the following growth mechanism. The heating of $\mathrm{PNCl}$ monomer to high temperatures and its interaction with DPT molecules can facilitate and initiate the opening of the cyclic structure to a chain linear polymer. FTIR measurements suggest the formation of a supramolecular assembly that is built from hydrogen bonds interaction between the two monomers at $260^{\circ} \mathrm{C}$ (Figure $2 \mathrm{~b}$; Supporting Information, Figure S7). The antisymmetric stretching vibration of PN ring was shifted from 783 to $806 \mathrm{~cm}^{-1}$ and the stretching vibration of the $\mathrm{N}-\mathrm{H}$ group in DPT fully disappeared. It is worth noting that the ring-opening reactions usually require the utilization of initiators/catalysts. ${ }^{[25]}$ Here, the hydrogen bonds network leads to the opening of the ring without any additional catalysts. Subsequently, the chlorine atoms linked to phosphorus are replaced by the active amine groups in DPT as depicted in Figure $2 \mathrm{~b}$. At $350^{\circ} \mathrm{C}$, the unreacted amine groups in DPT start to polymerize and establish a scaffold based on carbon and nitrogen. In this case, an ordered carbon-nitrogen structure that substitutes $-[\mathrm{PNR}]_{n}-$ polymer chains with a well-organized, dense, flat, and smooth morphology (Supporting Information, Figures S8,S9) is obtained from a polymerization in the molten phase at high temperature. The molten phase allows the two monomers to react similarly to the traditional organic chemistry approach owing to the molecules miscibility and reactivity. Therefore, as shown before, it is simple to tune the final elements ratio by adapting the initial monomers ratio. At higher calcination temperatures, the polymerization is followed by a full carbonization of the structure to DPN. Our results indicate that the materials compose from $\mathrm{P}-\mathrm{N}-\mathrm{C}$ bonds.

TGA in air was conducted to evaluate the stability of the new materials to oxidation and their suitability as fire- retardant materials. First, all the DPNs-550, with DPT:PNCl ratio ranging from $6: 1$ to $1: 6$, were analyzed to probe the effect of the elements ratio on the thermal stability (Figure $4 \mathrm{a}$ ). The $\mathrm{T}_{10}$ (the temperature at $10 \%$ material loss) strongly depends on the starting and final elements ratio and dramatically increases with higher $\mathrm{PNCl}$ amounts (inset in Figure $4 \mathrm{a}$ and the Supporting Information, Table S7). The best $\mathrm{T}_{10}, 747^{\circ} \mathrm{C}$, was obtained for the $\mathrm{D}_{1} \mathrm{PN}_{3}-550$ sample. At higher $\mathrm{PNCl}$ ratio, a small decrease of $\mathrm{T}_{10}$ to $731^{\circ} \mathrm{C}$ was obtained. Noticeably, the $\mathrm{T}_{10}$ of the carbon-nitrogen scaffold from DPT-550 shows a lower $\mathrm{T}_{10}$ value of $574{ }^{\circ} \mathrm{C}$ and the material was fully decomposed at about $700{ }^{\circ} \mathrm{C}$. The greater stability of the DPN materials can be attributed to the strong $\mathrm{P}-\mathrm{N}$ linear backbones within the structure which are known to be stable to oxidation.

We opted to further optimize the best sample $\left(\mathrm{D}_{1} \mathrm{PN}_{3}\right)$ by exploring final condensation temperatures from 450 to $850^{\circ} \mathrm{C}$ (Figure $4 \mathrm{~b}$; Supporting Information, Table S8). The increase of the condensation temperature from 450 to $650{ }^{\circ} \mathrm{C}$ results in an increase in $\mathrm{T}_{10}$, up to an impressive $795^{\circ} \mathrm{C}$ for $\mathrm{D}_{1} \mathrm{PN}_{3}-650$. Further increase in the condensation temperature of the synthesis to $750^{\circ} \mathrm{C}$ leads to a slight decrease in $\mathrm{T}_{10}$. The materials synthesized at $850^{\circ} \mathrm{C}$ show a similar behavior to the pristine carbon-nitrogen scaffold due to the massive loss of PN units within the structure as shown before. Therefore, based on these results, we conclude that $\mathrm{D}_{1} \mathrm{PN}_{3}-650$ exhibits the best stability to oxidation and flame-retardant properties. 
The fire-retardant behavior of $\mathrm{D}_{1} \mathrm{PN}_{3}-650$ was further evaluated by burning it for 30 and 60 min under the hot flame of an alcohol lamp (Figure 4c). Compared with the recent state-of-the-art fire-retardant carbon-based materials, ${ }^{[10 b]}$ our material displays an excellent stability enhancement and only a slight mass loss was obtained (Supporting Information, Figures S10, S11). Images of burned $\mathrm{D}_{1} \mathrm{PN}_{3}-650$ after soaking it in ethanol are shown in the Supporting Information, Figure S12. Importantly, the sample almost remained intact and the flame did not self-propagate. The FTIR, XPS, and SEM results (Supporting Information, Figures S13-S15) illustrate that the $-[\mathrm{PNR}]_{n}$ - polymeric chains remain even after 30 min burning, despite some $\mathrm{P}-\mathrm{O}$ species inevitably appearing. XPS data (Supporting Information, Figure S14) suggests that the carbon was barely oxidized. We proposed that the $\mathrm{P}$ is mainly oxidized, protecting the carbon from burning. Recently it was reported that heteroatoms insertion into carbon matrix may lead to the formation of noble carbons with very high resistance to oxidation. ${ }^{[7 \mathrm{~d}]}$ The chemical stability of $\mathrm{D}_{1} \mathrm{PN}_{3}-650$ was investigated by immersing it into strong acid and base. The material demonstrated high stability under these harsh condition as shown in Figure S16.

$\mathrm{UV} / \mathrm{Vis}$ and impedance spectroscopy measurements (Supporting Information, Figure S17) disclose that $\mathrm{D}_{1} \mathrm{PN}_{3}-650$ is a n-type semiconductor with a band gap of $1.45 \mathrm{eV}$ (Supporting Information, Figure S17). The electric conductivity of $\mathrm{D}_{1} \mathrm{PN}_{3}-650$ is slightly improved compared to DPT-550 (Supporting Information, Figure S18).

The thermal properties of the $\mathrm{D}_{1} \mathrm{PN}_{3}-650$ were then evaluated and the corresponding values for effective thermal conductivity $\left(\lambda_{\text {eff }}\right)$, diffusivity $(\kappa)$ and specific heat were $0.157( \pm 0.009) \mathrm{W} \mathrm{mK}^{-1}, \quad 0.31( \pm 0.05) \mathrm{mm}^{2} \mathrm{~s}^{-1}, \quad$ and $0.52( \pm$ $0.05) \mathrm{MJ} \mathrm{m}^{-3} \mathrm{~K}^{-1}$. It should be mentioned here that both the $\lambda_{\text {eff }}$ and $\kappa$ are possibly slightly overestimated due to the experimental set-up, where the carbonaceous foam was partially crushed. The low thermal diffusivity can be compared to some polymeric materials, silica or adobe bricks, corroborates well with the observed flame-retardant stability enhancement preventing the excessive propagation of the heat front through the material as displayed in Figure 4c. Analysis of mercury porosimetry shows that the $\mathrm{D}_{1} \mathrm{PN}_{3}-650$ sample possesses a rather small pore volume $\left(0.144 \mathrm{~cm}^{3} \mathrm{~g}^{-1}\right)$ and a low mesoporosity (only a small fraction of mesopores around $3.5 \mathrm{~nm}$ in size), which results the value of $\lambda_{\text {eff }}$ that is not as low as anticipated $\left(\ll 0.100 \mathrm{~W} \mathrm{mK}^{-1}\right)$.

In conclusion, we demonstrate a unique and straightforward approach involving a molten-state step to synthesize CNP materials with unprecedentedly high amount of phosphorus, up to $32 \mathrm{wt} \%$, and controllable elemental composition and chemical properties. To do so, we used two monomers that melt at high temperatures and establish a mixture that is a homogenous liquid up to $400^{\circ} \mathrm{C}$. The molten-state stage leads to excellent monomers miscibility at high temperatures, allowing their reaction as in solution and prevents $\mathrm{PNCl}$ evaporation. Detailed structural analysis of the molten-state intermediates and the final carbon-nitrogen-phosphorus materials with various monomers ratio and calcination temperatures reveals that the reaction occurs by the opening of hexachlorophosphazene rings, followed by the replacement of the chlorine atoms by amine groups of the DPT monomer at the molten-state stage. We demonstrated that the chemical composition and the thermal stability to oxidation at high temperature can be tuned by the starting monomers ratio and the final calcination temperature. Consequently, the materials exhibit great resistance to oxidation and for the best composite up to $90 \%$ of the materials are preserved at $800^{\circ} \mathrm{C}$ under air. We believe that the moltenstate approach opens the opportunity to overcome some of the traditional solid-state limitations in the synthesis of new materials with controllable and tunable elemental composition as well as variable chemical and electronic properties toward their utilization in fire-retardant materials and electrochemical devices.

\section{Acknowledgements}

M.S. thanks the financial support of the Israel National Research Center for Electrochemical Propulsion (INREP), NSF of China (No. 51572125) and PAPD of Jiangsu. NMR spectroscopic calculations were performed using HPC resources from GENCI-IDRIS (Grant 097535). The French Région Ile de France-SESAME program is acknowledged for financial support (700 MHz spectrometer).

\section{Conflict of interest}

The authors declare no conflict of interest.

Keywords: carbon-nitrogen-phosphorus materials . fire-retardant materials - molten-state reactions . tunable elemental composition

How to cite: Angew. Chem. Int. Ed. 2018, 57, 9764-9769 Angew. Chem. 2018, 130, 9912-9917

[1] M.-M. Titirici, R. J. White, N. Brun, V. L. Budarin, D. S. Su, F. del Monte, J. H. Clark, M. J. MacLachlan, Chem. Soc. Rev. 2015, 44, 250-290.

[2] a) W. H. Shin, H. M. Jeong, B. G. Kim, J. K. Kang, J. W. Choi, Nano Lett. 2012, 12, 2283-2288; b) W. Shen, C. Wang, Q. Xu, H. Liu, Y. Wang, Adv. Energy Mater. 2015, 5, 1400982; c) T. Takenobu, T. Takano, M. Shiraishi, Y. Murakami, M. Ata, H. Kataura, Y. Achiba, Y. Iwasa, Nat. Mater. 2003, 2, 683.

[3] G. Wu, C. Dai, D. Wang, D. Li, N. Li, J. Mater. Chem. 2010, 20, 3059-3068.

[4] a) P. Nath, S. Chowdhury, D. Sanyal, D. Jana, Carbon 2014, 73, 275-282; b) F. Arcudi, L. Đorđević, M. Prato, Angew. Chem. Int. Ed. 2016, 55, 2107-2112; Angew. Chem. 2016, 128, $2147-$ 2152.

[5] a) L. Yang, S. Jiang, Y. Zhao, L. Zhu, S. Chen, X. Wang, Q. Wu, J. Ma, Y. Ma, Z. Hu, Angew. Chem. Int. Ed. 2011, 50, 7132-7135; Angew. Chem. 2011, 123, 7270-7273; b) Y. Liu, S. Chen, X. Quan, H. Yu, J. Am. Chem. Soc. 2015, 137, 11631-11636; c) Q. Pang, J. Tang, H. Huang, X. Liang, C. Hart, K. C. Tam, L. F. Nazar, Adv. Mater. 2015, 27, 6021-6028.

[6] D. Guo, R. Shibuya, C. Akiba, S. Saji, T. Kondo, J. Nakamura, Science 2016, 351, 361-365.

[7] a) S. Park, Y. Hu, J. O. Hwang, E.-S. Lee, L. B. Casabianca, W. Cai, J. R. Potts, H.-W. Ha, S. Chen, J. Oh, Nat. Commun. 2012, 3, 
638; b) C. Zhang, N. Mahmood, H. Yin, F. Liu, Y. Hou, Adv Mater. 2013, 25, 4932-4937; c) D. Usachov, O. Vilkov, A Gruneis, D. Haberer, A. Fedorov, V. Adamchuk, A. Preobrajenski, P. Dudin, A. Barinov, M. Oehzelt, Nano Lett. 2011, 11 , 5401-5407; d) M. Antonietti, M. Oschatz, Adv. Mater. 2018, 30, 1706836

[8] a) L. Qu, Y. Liu, J.-B. Baek, L. Dai, ACS Nano 2010, 4, 1321 1326; b) Q. Li, S. Zhang, L. Dai, L.-s. Li, J. Am. Chem. Soc. 2012 134, 18932 -18935; c) R. Li, Z. Wei, X. Gou, ACS Catal. 2015, 5 , $4133-4142$.

[9] a) K. N. Wood, R. O'Hayre, S. Pylypenko, Energy Environ. Sci. 2014, 7, 1212-1249; b) K. Gong, F. Du, Z. Xia, M. Durstock, L. Dai, Science 2009, 323, 760-764; c) J. Song, Z. Yu, M. L. Gordin, S. Hu, R. Yi, D. Tang, T. Walter, M. Regula, D. Choi, X. Li, Nano Lett. 2014, 14, 6329-6335; d) Z. Yu, J. Song, M. L. Gordin, R. Yi, D. Tang, D. Wang, Adv. Sci. 2015, 2, 1400020.

[10] a) L. Dong, C. Hu, L. Song, X. Huang, N. Chen, L. Qu, Adv. Funct. Mater. 2016, 26, 1470-1476; b) C. Hu, J. Xue, L. Dong, Y. Jiang, X. Wang, L. Qu, L. Dai, ACS Nano 2016, 10, 1325-1332.

[11] a) Y. Zhang, T. Mori, J. Ye, M. Antonietti, J. Am. Chem. Soc. 2010, 132, 6294-6295; b) S. Guo, Z. Deng, M. Li, B. Jiang, C. Tian, Q. Pan, H. Fu, Angew. Chem. Int. Ed. 2016, 55, 1830-1834 Angew. Chem. 2016, 128, 1862-1866; c) T. Y. Ma, J. Ran, S. Dai, M. Jaroniec, S. Z. Qiao, Angew. Chem. Int. Ed. 2015, 54, $4646-$ 4650; Angew. Chem. 2015, 127, 4729-4733; d) S. Yang, L. Peng, P. Huang, X. Wang, Y. Sun, C. Cao, W. Song, Angew. Chem. Int Ed. 2016, 55, 4016-4020; Angew. Chem. 2016, 128, 4084-4088.

[12] a) X. Wang, K. Maeda, A. Thomas, K. Takanabe, G. Xin, J. M. Carlsson, K. Domen, M. Antonietti, Nat. Mater. 2009, 8, 76-80; b) Y. Wang, X. Wang, M. Antonietti, Angew. Chem. Int. Ed. 2012, 51, 68-89; Angew. Chem. 2012, 124, 70-92.

[13] J. Zhang, L. Dai, Angew. Chem. Int. Ed. 2016, 55, 13296-13300; Angew. Chem. 2016, 128, 13490-13494.

[14] a) D.-S. Yang, D. Bhattacharjya, S. Inamdar, J. Park, J.-S. Yu, J. Am. Chem. Soc. 2012, 134, 16127-16130; b) Z. W. Liu, F. Peng, H. J. Wang, H. Yu, W. X. Zheng, J. Yang, Angew. Chem. Int. Ed. 2011, 50, 3257-3261; Angew. Chem. 2011, 123, 3315-3319.

[15] a) S. Rothemund, I. Teasdale, Chem. Soc. Rev. 2016, 45, 52005215 ; b) A. B. Chaplin, J. A. Harrison, P. J. Dyson, Inorg. Chem. 2005, 44, 8407-8417.

[16] a) C. Li, Z. Chen, A. Kong, Y. Ni, F. Kong, Y. Shan, J. Mater. Chem. A 2018, 6, 4145-4151; b) B. Wicklein, A. Kocjan, G. Salazar-Alvarez, F. Carosio, G. Camino, M. Antonietti, L. Bergström, Nat. Nanotechnol. 2015, 10, 277-283.
[17] a) H. R. Allcock, Chem. Mater. 1994, 6, 1476-1491; b) H. R. Allcock, Chemistry and applications of polyphosphazenes, Wiley-Interscience, New York, 2003; c) A. K. Andrianov, J. Chen, M. P. LeGolvan, Macromolecules 2004, 37, 414-420.

[18] S. Gaan, G. Sun, K. Hutches, M. H. Engelhard, Polym. Degrad. Stab. 2008, 93, 99-108.

[19] F. Gao, L. Tong, Z. Fang, Polym. Degrad. Stab. 2006, 91, 12951299.

[20] a) D. Deng, X. Pan, L. Yu, Y. Cui, Y. Jiang, J. Qi, W.-X. Li, Q. Fu, X. Ma, Q. Xue, G. Sun, X. Bao, Chem. Mater. 2011, 23, $1188-$ 1193; b) L. Panchakarla, K. Subrahmanyam, S. Saha, A. Govindaraj, H. Krishnamurthy, U. Waghmare, C. Rao, $A d v$. Mater. 2009, 21, 4726-4730.

[21] Á. Díaz-Ortiz, J. Elguero, C. Foces-Foces, A. de la Hoz, A. Moreno, M. del Carmen Mateo, A. Sánchez-Migallón, G. Valiente, New J. Chem. 2004, 28, 952-958.

[22] a) J. Sehnert, K. Baerwinkel, J. Senker, J. Phys. Chem. B 2007, 111, $10671-10680$; b) B. V. Lotsch, M. Döblinger, J. Sehnert, L. Seyfarth, J. Senker, O. Oeckler, W. Schnick, Chem. Eur. J. 2007, 13, 4969-4980; c) A. Schwarzer, T. Saplinova, E. Kroke, Coord. Chem. Rev. 2013, 257, 2032-2062.

[23] J. Bill, J. Seitz, G. Thurn, J. Dürr, J. Canel, B. Janos, A. Jalowiecki, D. Sauter, S. Schempp, H. Lamparter, Phys. Status Solidi A 1998, 166, 269-296.

[24] a) S. W. Bartlett, S. J. Coles, D. B. Davies, M. B. Hursthouse, H. İbişoğlu, A. Kiliç, R. A. Shaw, İ. Ün, Acta Crystallogr. Sect. B 2006, 62, 321-329; b) I. Sirotin, Y. V. Bilichenko, K. Brigadnov, V. Kireev, O. Suraeva, R. Borisov, Russ. J. Appl. Chem. 2013, 86, $1903-1912$.

[25] a) Z.-M. Tun, A. J. Heston, M. J. Panzner, V. Scionti, D. A. Medvetz, B. D. Wright, N. A. Johnson, L. Li, C. Wesdemiotis, P. L. Rinaldi, Inorg. Chem. 2016, 55, 3283-3293; b) A. J. Heston, M. J. Panzner, W. J. Youngs, C. A. Tessier, Inorg. Chem. 2005, 44, $6518-6520$

[26] CCDC 224695 contains the supplementary crystallographic data for this paper. These data can be obtained free of charge from The Cambridge Crystallographic Data Centre.

Manuscript received: May 6, 2018

Revised manuscript received: May 25, 2018

Accepted manuscript online: May 29, 2018

Version of record online: July 5, 2018 


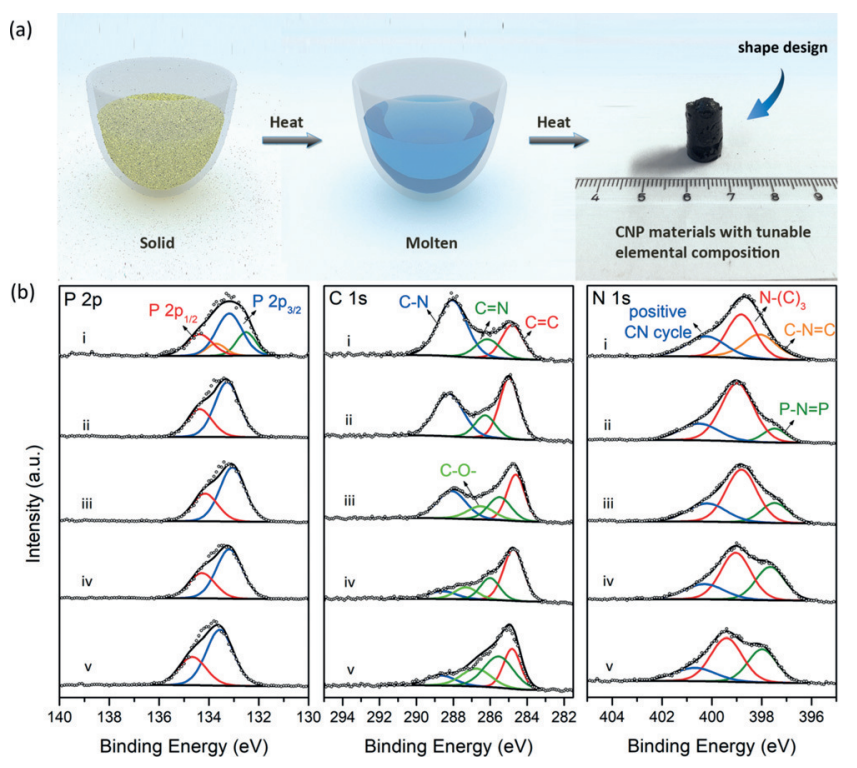

Figure 1. a) Illustration of the process for preparing DPN samples involving a molten-state step. b) High-resolution $P 2 \mathrm{p}, \mathrm{C}$ 1s, N 1s XPS spectra of i) $D_{6} P N_{1}-550$, ii) $D_{3} P N_{1}-550$, iii) $D_{1} P N_{1}-550$, iv) $D_{1} P N_{3}-550$, v) $\mathrm{D}_{1} \mathrm{PN}_{6}-550$.

(a)

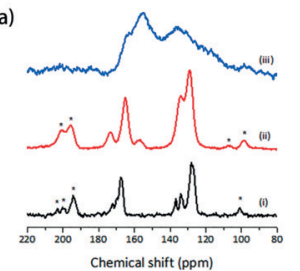

(b)

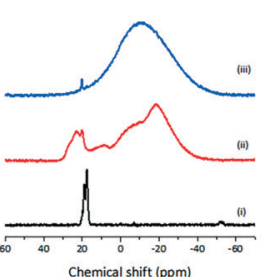

(c)

350

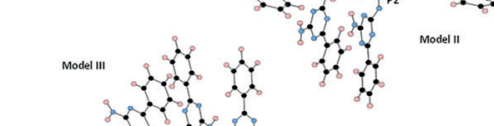

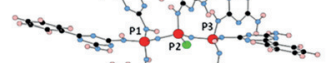

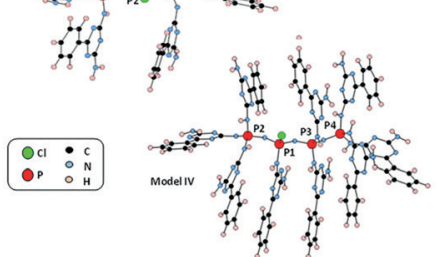

Figure 3. a) ${ }^{13} \mathrm{C} C P$ MAS NMR spectra of i) DPT and reaction products with $\mathrm{PNCl}$ (molar ratio of DPT:PNCl of 1:3) at ii) $260^{\circ} \mathrm{C}$ and iii) $550^{\circ} \mathrm{C}$ b) ${ }^{31} \mathrm{P}$ MAS NMR spectra of i) $\mathrm{PNCl}$ and reaction products with DPT (molar ratio of DPT:PNCl of $1: 3$ ) at ii) $260^{\circ} \mathrm{C}$, and iii) $550^{\circ} \mathrm{C}$. c) Representation of the models I, II, III, and IV obtained through geometry optimization.
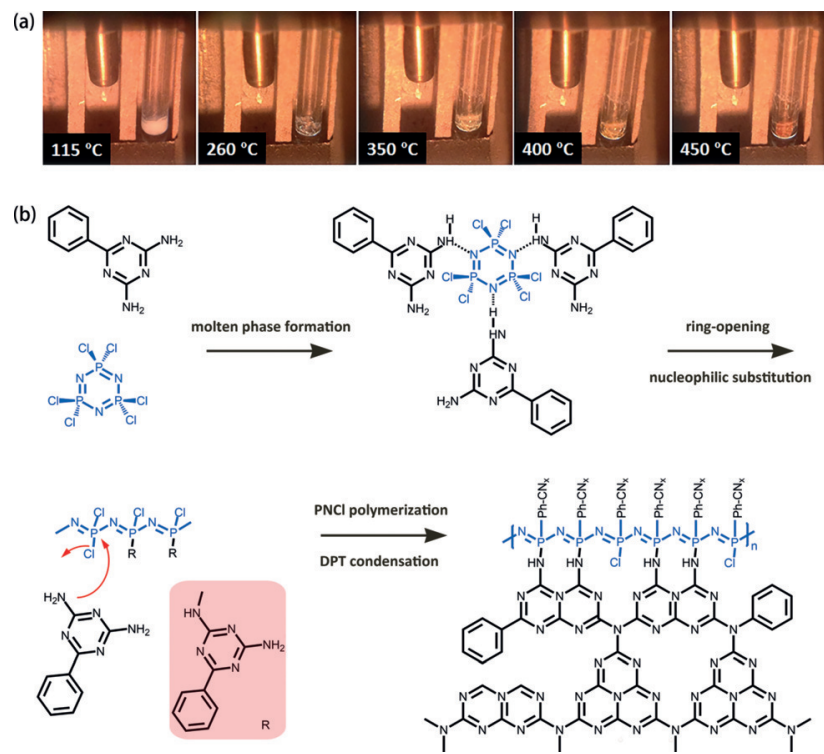

Figure 2. a) Melting of the DPT-PNCl precursor seen in the melting point apparatus at controlled temperatures. b) Proposed reaction path of CNP materials.
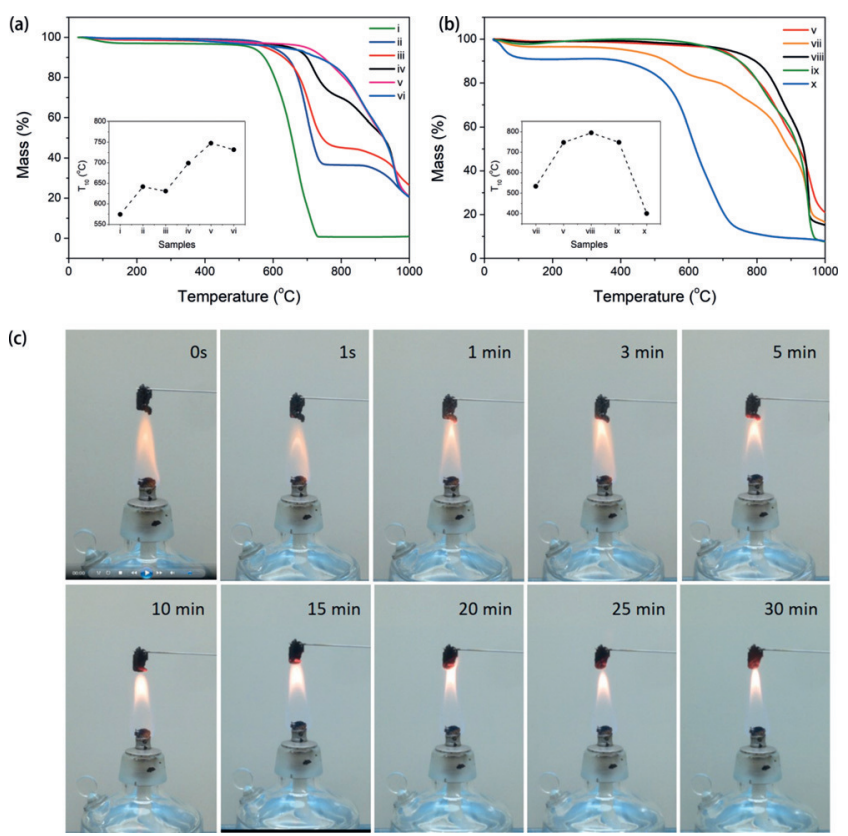

Figure 4. TGA curves of DPN samples synthesized in a) various raw materials ratio, and b) various calcination temperature measured in air with a heating rate of $10^{\circ} \mathrm{Cmin}^{-1}$. The insets are the $T_{10}$ temperatures vs. samples, i) DPT-550, ii) $D_{6} P N_{1}-550$, iii) $D_{3} P N_{1}-550$, iv) $D_{1} P N_{1}-550$, v) $D_{1} P N_{3}-550$, vi) $D_{1} P N_{6}-550$, vii) $D_{1} P N_{3}-450$, viii) $D_{1} P N_{3}-650$, ix) $D_{1} P N_{3}-750$

x) $D_{1} P_{3}-850$. c) Photographs of the $D_{1} P N_{3}-650$ exposed to a flame (alcohol lamp) after various exposition times. 